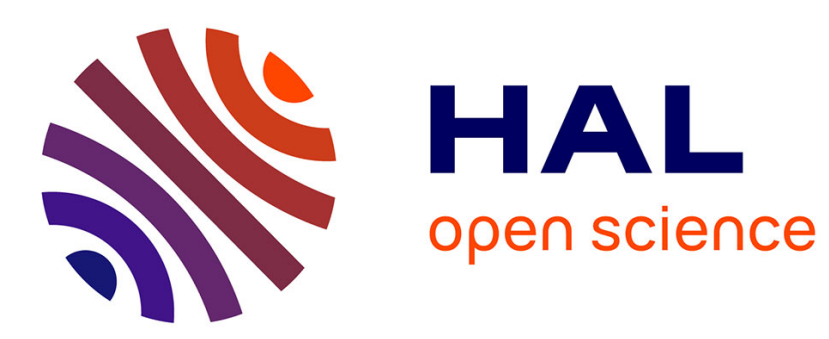

\title{
Ductility of Ultra High Purity Copper
}

S. Fujiwara, K. Abiko

\section{To cite this version:}

S. Fujiwara, K. Abiko. Ductility of Ultra High Purity Copper. Journal de Physique IV Proceedings, 1995, 05 (C7), pp.C7-295-C7-300. 10.1051/jp4:1995735 . jpa-00254029

\section{HAL Id: jpa-00254029 https://hal.science/jpa-00254029}

Submitted on 1 Jan 1995

HAL is a multi-disciplinary open access archive for the deposit and dissemination of scientific research documents, whether they are published or not. The documents may come from teaching and research institutions in France or abroad, or from public or private research centers.
L'archive ouverte pluridisciplinaire HAL, est destinée au dépôt et à la diffusion de documents scientifiques de niveau recherche, publiés ou non, émanant des établissements d'enseignement et de recherche français ou étrangers, des laboratoires publics ou privés. 


\title{
Ductility of Ultra High Purity Copper
}

\author{
S. Fujiwara and K. Abiko*
}

Steel R\&D, Nishin Steel Co., Ltd, 11-1 Shohwa-Cho, Kure-City Hiroshima 737, Japan

* Institute for Materials Research, Tohoku University, Sendai 980, Japan

\begin{abstract}
The ductility of vltra-high purity copper at elevated temperatures was investigated : purity $99.9999 \%$ $(6 \mathrm{~N})$ and $99.999999 \%(8 \mathrm{~N})$. Tensile tests were conducted at temperatures ranging from $293 \mathrm{~K}$ to $1073 \mathrm{~K}$ at strain rates of $4.2 \times 10^{-5} \mathrm{~s}^{-1}$ in a high vacuum. The results are discussed in comparison with those for $99.9 \%$ (3N) copper. Ductility at intermediate temperatures was improved by an increase in purity. The temperature at which ductility dropped decreased with increases in purity. Even at the ultra-high purity of $8 \mathrm{~N}$, a small ductility drop was observed at $423 \mathrm{~K}$. A small number of micro voids were observed on the grain boundaries of $8 \mathrm{~N}$ specimens after the test at $423 \mathrm{~K} .6 \mathrm{~N}$ and $8 \mathrm{~N}$ copper have nearly same sulphur content of about $0.015 \mathrm{ppm}$. The intermediate temperature embrittlement of these coppers might be affected not only by sulphur content, but also by total impurity content.
\end{abstract}

\section{INTRODUCTION}

Copper has been one of the most popular and important base metals for a long time, because of its excellent electric and thermal conductivity. However, the properties of copper such as electric and thermal conductivity do not reach the levels needed for recent industrial use. In order to improve such properties, copper has been refined. Recently, copper purified to more than $99.9999 \%(6 \mathrm{~N})$ has been commercially produced by a special purifying process, which combines electrolytic refining, electron beam refining and vacuum melting. The use of high purity copper has been tried recently in highly technical fields, such as superconductors, electron accelerators and interconnections in advanced IC. In these fields, copper with better mechanical properties without the sacrifice of conductivity at high temperatures is also required [1,2]. However, a ductility drop in pure copper and some copper alloys at about 600 to $800 \mathrm{~K}$ has been reported by many researchers [3-14]. This phenomenon is called intermediate temperature embrittlement due to intergranular failure. Ductility at intermediate temperatures decreases with the decrease in strain rate and with the increase in grain size [5-7,12]. Suzuki and Ito [9] found that reducing the sulphur content in pure copper reduced the effect of intermediate temperature embrittlement at a strain rate of $4.2 \times 10^{-4} \mathrm{~s}^{-1}$. Ito, Kanno, Okamoto and Yamamoto [10] reported that ductility at intermediate temperatures decreased with the increase in sulphur content, and the temperature of the ductility drop decreased with an decrease in sulphur content at a low strain rate of $4.2 \times 10^{-5} \mathrm{~s}^{-1}$. However, they were only interested in sulphur content and not in other impurity elements.

The purposes of the present study are to investigate the ductility of ultra-high purity copper of $6 \mathrm{~N}$ and $8 \mathrm{~N}$ from room temperature to elevated temperatures, and to discuss the effect, not only of sulphur content, but also of total impurity content on the intermediate temperature embrittlement of pure copper.

\section{EXPERIMENTAL PROCEDURES}

The ultra-high purity copper of $6 \mathrm{~N}$ and $8 \mathrm{~N}$ used in the present study was purified by the Japan Energy Co., Ltd. Commercial purity copper rod of $99.9 \%(3 \mathrm{~N})$ purity was used for comparison with the ductility of $6 \mathrm{~N}$ and $8 \mathrm{~N}$ copper. Table 1 shows the results of the chemical analysis of the specimens determined by glow 
Table 1: Results of chemical analysis of the pure coppers (mass ppm)

\begin{tabular}{cccc}
\hline Element & $3 \mathrm{~N}-\mathrm{Cu}$ & $6 \mathrm{~N}-\mathrm{Cu}$ & $8 \mathrm{~N}-\mathrm{Cu}$ \\
\hline $\mathrm{C}$ & $<1$ & $<1$ & $<1$ \\
$\mathrm{~S}$ & 4.6 & 0.014 & 0.015 \\
$\mathrm{~N}$ & $<1$ & $<1$ & $<1$ \\
$\mathrm{O}$ & 240 & 0.8 & $<0.1$ \\
$\mathrm{H}$ & 0.22 & 0.10 & 0.03 \\
$\mathrm{Ag}$ & 15 & 0.32 & 0.011 \\
$\mathrm{Al}$ & 0.006 & 0.14 & 0.003 \\
$\mathrm{Si}$ & 0.021 & 0.068 & 0.023 \\
$\mathrm{P}$ & 0.51 & 0.012 & $<0.005$ \\
$\mathrm{Ti}$ & $<0.005$ & 0.020 & 0.004 \\
$\mathrm{Cr}$ & 0.009 & 0.12 & $<0.002$ \\
$\mathrm{Mn}$ & 0.19 & 0.006 & $<0.002$ \\
$\mathrm{Fe}$ & 5.5 & 0.35 & 0.002 \\
\hline
\end{tabular}

\begin{tabular}{cccl}
\hline Element & $3 \mathrm{~N}-\mathrm{Cu}$ & $6 \mathrm{~N}-\mathrm{Cu}$ & $8 \mathrm{~N}-\mathrm{Cu}$ \\
\hline $\mathrm{Co}$ & 0.30 & 0.001 & $<0.001$ \\
$\mathrm{Ni}$ & 2.2 & 0.063 & $<0.002$ \\
$\mathrm{Zn}$ & 0.28 & $<0.005$ & $<0.005$ \\
$\mathrm{As}$ & 0.40 & $<0.01$ & $<0.01$ \\
$\mathrm{Cd}$ & $<0.005$ & $<0.01$ & $<0.01$ \\
$\mathrm{Sn}$ & 10 & $<0.01$ & $<0.01$ \\
$\mathrm{Sb}$ & 0.43 & $<0.005$ & $<0.005$ \\
$\mathrm{~Pb}$ & 1.4 & $<0.002$ & $<0.002$ \\
$\mathrm{Bi}$ & 0.069 & $<0.001$ & $<0.001$
\end{tabular}

Each copper rod of different purity was cold swaged from $8.0 \mathrm{~mm}$ to $6.5 \mathrm{~mm}$ in diameter. Specimens for the tensile tests of $20 \mathrm{~mm}$ gauge length and $3 \mathrm{~mm}$ diameter were machined from the round rods of $6.5 \mathrm{~mm}$ diameter. Every specimen was annealed for $1.8 \mathrm{ks}$ at $573 \mathrm{~K}$ at a high vacuum of $1.3 \times 10^{-2} \mathrm{~Pa}$. The average grain size was $30 \mu \mathrm{m}$ for $3 \mathrm{~N}, 50 \mu \mathrm{m}$ for $6 \mathrm{~N}$ and $100 \mu \mathrm{m}$ for $8 \mathrm{~N}$ after annealing. Tensile tests were carried out at the initial strain rate of $4.2 \times 10^{-5} \mathrm{~s}^{-1}$ between $293 \mathrm{~K}$ and $1073 \mathrm{~K}$ at a high vacuum of $7 \times 10^{-4} \mathrm{~Pa}$. The reduction in area (RA) after tensile test was used as the indicator of ductility. Scanning electron microscopy (SEM) of the fractured surfaces was carried out on several specimens after the tensile tests. The microstructure near the fracture surface after the tensile tests was observed to confirm the formation of cavities on grain boundaries and dynamic recrystallization by deformation.

\section{RESULTS}

\subsection{Ductility at Room Temperature}

Figure 1 shows stress-strain curves of different purity coppers tested at room temperature. Yield stress and maximum stress of ultra-high purity copper of $6 \mathrm{~N}$ and $8 \mathrm{~N}$ are lower than those of $3 \mathrm{~N}$ copper. The RA of ultra-high purity copper, $91 \%$ for $6 \mathrm{~N}$ and $96 \%$ for $8 \mathrm{~N}$, is higher than that of commercial copper, $82 \%$ for $3 \mathrm{~N}$. However, the elongation of $8 \mathrm{~N}$ copper is slightly lower than that of $6 \mathrm{~N}$ copper. This phenomenon might be caused by the effect of grain size. The ductility of pure copper at room temperature increases with the decrease in impurities. The significant difference between $3 \mathrm{~N}$ copper and $6 \mathrm{~N}, 8 \mathrm{~N}$ copper is especially recognizable.

\subsection{Ductility at Elevated Temperatures}

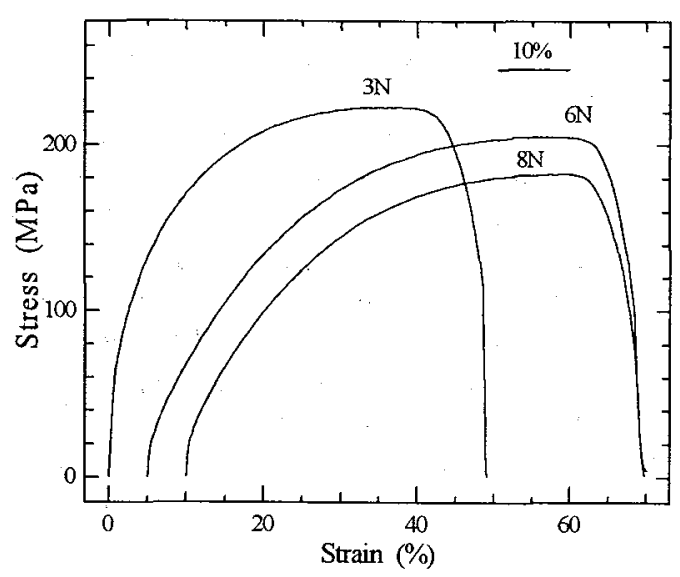

Figure 1 Stress-strain curves of pure copper at room temperature under the strain rate of $4.2 \times 10^{-5}$.

Figures 2 and 3 show the stress-strain curves of $6 \mathrm{~N}$ and $8 \mathrm{~N}$ copper at elevated temperatures at a strain rate of $4.2 \times 10^{-5} \mathrm{~s}^{-1}$. Above $473 \mathrm{~K}$ for $6 \mathrm{~N}$ copper and above $523 \mathrm{~K}$ for $8 \mathrm{~N}$ copper, the stress-strain curves show the typical shape of dynamic recrystallization [15-21]. After work hardening, the stress decreases, then increases slightly, and some peaks of stress are observed. The number of stress peaks increases with an increase in test temperature. 
On the other hand, the stress-strain curves of $6 \mathrm{~N}$ and $8 \mathrm{~N}$ coppers at $873 \mathrm{~K}$ and $1073 \mathrm{~K}$ become different from those accompanying typical dynamic recrystallization. At these temperature ranges, decrease of stress after work hardening is very fast. Then, the curves look like saw teeth. The same behaviour cannot be observed in $3 \mathrm{~N}$ copper, because of its low ductility at elevated temperatures, as described below. In ultra-high purity $6 \mathrm{~N}$ and $8 \mathrm{~N}$ coppers, the velocities of dynamic recrystallization might be very fast, due to the rapid rearrangement of dislocations accumulated by deformation.

The work hardening rate is very high at $423 \mathrm{~K}$ for $6 \mathrm{~N}$ copper and $373 \mathrm{~K}$ for $8 \mathrm{~N}$ copper. The total elongation of these coppers is small at each temperature. This phenomenon might be related to ductility drop, as described below.

Figure 4 shows the effect of test temperature on RA at temperatures ranging from $273 \mathrm{~K}$ to $1073 \mathrm{~K}$. The RA of $3 \mathrm{~N}$ copper drops remarkably above $473 \mathrm{~K}$. The RA of $3 \mathrm{~N}$ copper above $673 \mathrm{~K}$ falls lower than $20 \%$. Although these ductility drops are caused by intermediate temperature embrittlement, no recovery of RA in $3 \mathrm{~N}$ copper at a temperature of $1073 \mathrm{~K}$ is observed. The RA drop is observed in $6 \mathrm{~N}$ copper from 423 to $523 \mathrm{~K}$, and in $8 \mathrm{~N}$ copper from 373 to $473 \mathrm{~K}$. However, RA of the $6 \mathrm{~N}$ and $8 \mathrm{~N}$ coppers is quite high, almost $100 \%$ above $523 \mathrm{~K}$ and $473 \mathrm{~K}$, respectively. In these temperature ranges, chisel point fracture is observed in $6 \mathrm{~N}$ and $8 \mathrm{~N}$ coppers. The ductility drop is improved by an increase in purity. The temperature of the ductility drop decreases with the increase in purity.

Figure 5 shows the microstructures of fractured surfaces after the tensile test at RA drop temperature at a strain rate of $4.2 \times 10^{-5} \mathrm{~s}^{-1}$; the test temperatures were $873 \mathrm{~K}$ for $3 \mathrm{~N}$ copper, $473 \mathrm{~K}$ for $6 \mathrm{~N}$ copper and $423 \mathrm{~K}$ for $8 \mathrm{~N}$ copper. The fractured surface of $3 \mathrm{~N}$ copper tested at 873K shows intergranular fracture. A lot of small dimples on the grain boundaries can be observed. A lot of intergranular failures can be also observed in the microstructure of $3 \mathrm{~N}$ copper in (d). The cavities nucleated on the grain boundaries at first. They grew and chained together during deformation.

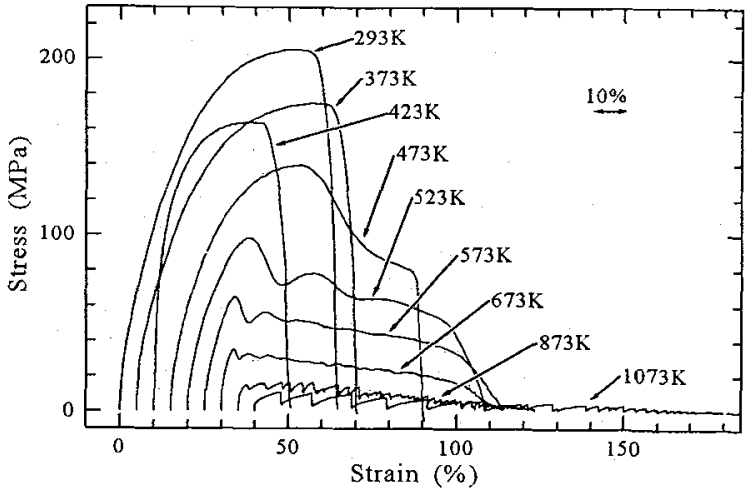

Figure 2 Stress-strain curves of $6 \mathrm{~N}$ copper at elevated temperature

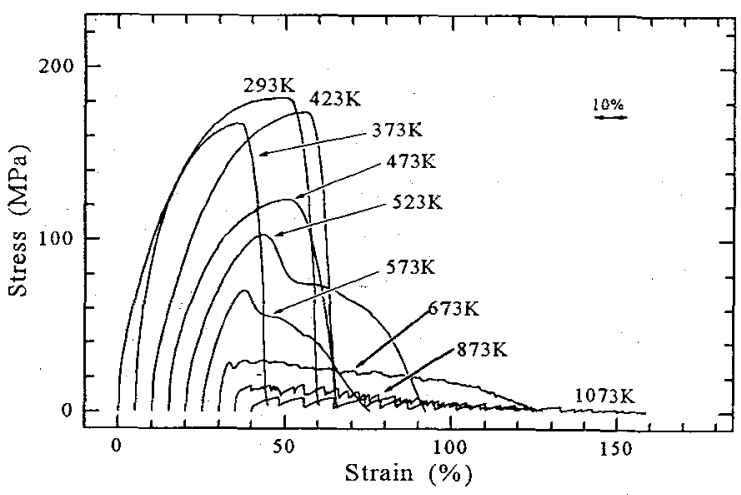

Figure 3 Stress-strain curves of $8 \mathrm{~N}$ copper at elevated temperature Test tem perature ( $\mathrm{C}$ )

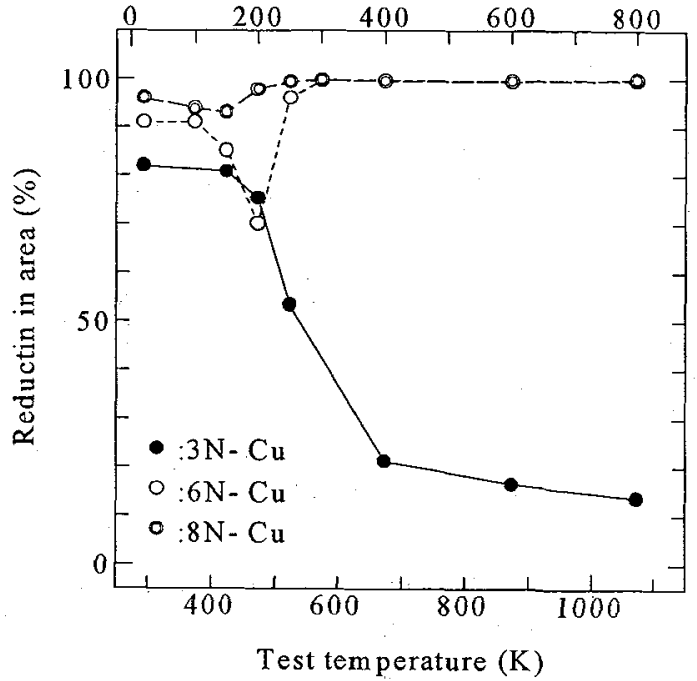

Figure 4 Effect of test temperature on reduction in area under the strain rate of $4.2 \times 10^{-5}$. 

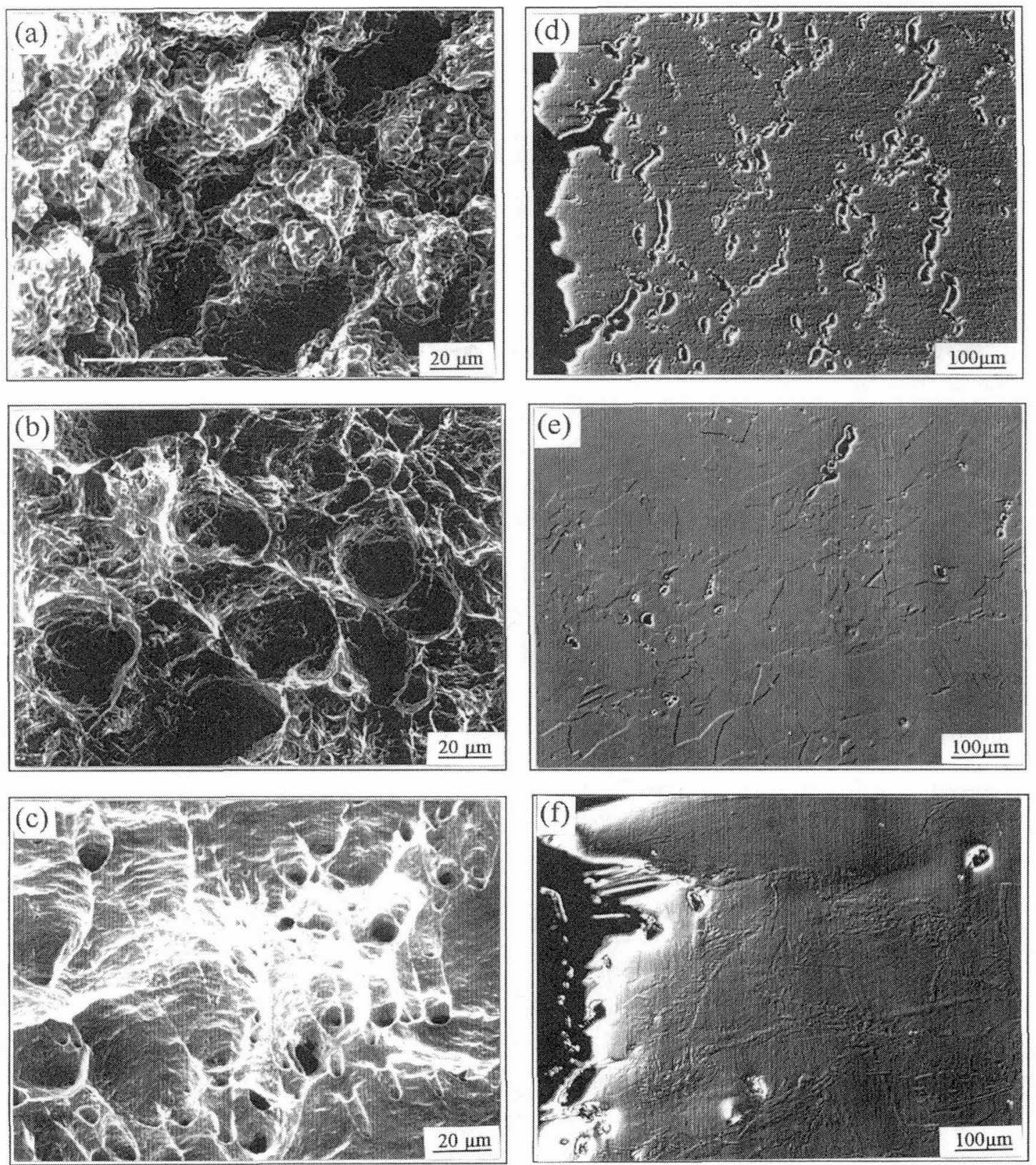

Figure 5 Fractured surfaces and microstructures after the tensile tests at (a) (d) $873 \mathrm{~K}$ for $3 \mathrm{~N}$ copper, (b) (e) $473 \mathrm{~K}$ for $6 \mathrm{~N}$ copper and (c) (f) $423 \mathrm{~K}$ for $8 \mathrm{~N}$ copper.

Finally, intergranular failure occurred at intermediate temperatures. The fracture surfaces of ultra-high purity copper of $6 \mathrm{~N}$ tested at $473 \mathrm{~K}$ and $8 \mathrm{~N}$ at $423 \mathrm{~K}$ show ductile fractures. No intergranular surfaces can be observed. However, in the microstructure of $6 \mathrm{~N}$ copper tested at $473 \mathrm{~K}$, intergranular failures can be observed. In the microstructure of $8 \mathrm{~N}$ copper tested at $423 \mathrm{~K}$, only a few cavities can be observed. These 
cavities are located on the grain boundaries. Although the number of intergranular failures decreases with the increase in purity, fracture at intermediate temperatures is caused in every case by the cavities nucleated at grain boundaries.

\section{DISCUSSION}

In the present research, no recovery of RA in $3 \mathrm{~N}$ copper at a temperature of $1073 \mathrm{~K}$ is observed. This result is different from the results in some former reports [4-14]. There are two reasons to explain this phenomenon. One is the lower purity of $3 \mathrm{~N}$ copper used in the present research, and the other is the lower strain rate in present research. In the most of the former reports, copper of purity greater than $4 \mathrm{~N}$ was used, and strain rates over $10^{-3} \mathrm{~s}^{-1}$ were chosen. In our view, the ductility drop of $3 \mathrm{~N}$ copper above $473 \mathrm{~K}$ in the present research is caused by intermediate temperature embrittlement, although no recovery of RA to temperature of $1073 \mathrm{~K}$ is recognized. Generally, the intermediate temperature embrittlement of pure copper and copper alloys is caused by intergranular failure due to cavities nucleated on the grain boundaries. It is thought that the nucleation of cavities on the grain boundaries is caused by boundary sliding and piling-up of the dislocations on the grain boundaries through the slip line in the grains [3, 22-24]. Boundary sliding and the diffusion of the defects to the grain boundaries occur more easily with increasing temperature. On the other hand, dynamic recrystallizations also occur more easily with increasing temperature. Dynamic recrystallization along the grain boundaries occurs more easily than in the grains. So ductility improves at higher temperatures due to dynamic recrystallization.

Kanno and Ito [12] found that decreasing sulphur content in pure copper made recrystallization temperatures lower. That made the ductility of pure copper at intermediate temperatures higher and caused the temperature of the ductility drop to fall. In the present research, ductility at intermediate temperatures was improved by an increase in purity. The temperature of the ductility drop decreased with the increase in purity. However, the sulphur content of ultra-high purity copper of $6 \mathrm{~N}$ and $8 \mathrm{~N}$ is nearly same. Although sulphur is one of the most important elements in recrystallization behaviour, the improvement in intermediate temperature embrittlement is caused not only by sulphur content, but also by total impurity content through the decreasing dynamic recrystallization temperature. Figure 6 shows the static recrystallization behaviour of pure coppers after being cold deformed $83 \%$ in area. The static recrystallization temperature is about $400 \mathrm{~K}$ for $8 \mathrm{~N}$ copper, $420 \mathrm{~K}$ for $6 \mathrm{~N}$ copper and $500 \mathrm{~K}$ for $3 \mathrm{~N}$ copper. The static recrystallization temperature decreases with the increase in purity. Although dynamic recrystallization behaviour is not quite the same as static recrystallization behaviour, the dynamic recrystallization temperature of ultra-high purity coppers must be lower than that of coppers of industrial purity. In fact, the stress-strain curve of $6 \mathrm{~N}$ copper at $473 \mathrm{~K}$ suggests the dynamic recrystallization in Figure 2. Although the stressstrain curve of $8 \mathrm{~N}$ copper at $423 \mathrm{~K}$ does not suggest the dynamic recrystallization in Figure 3 , some dynamically recrystallized small grains are observed along the grain boundaries near the fractured surface of $8 \mathrm{~N}$ copper tested at $423 \mathrm{~K}$ in Figure 5 (f).

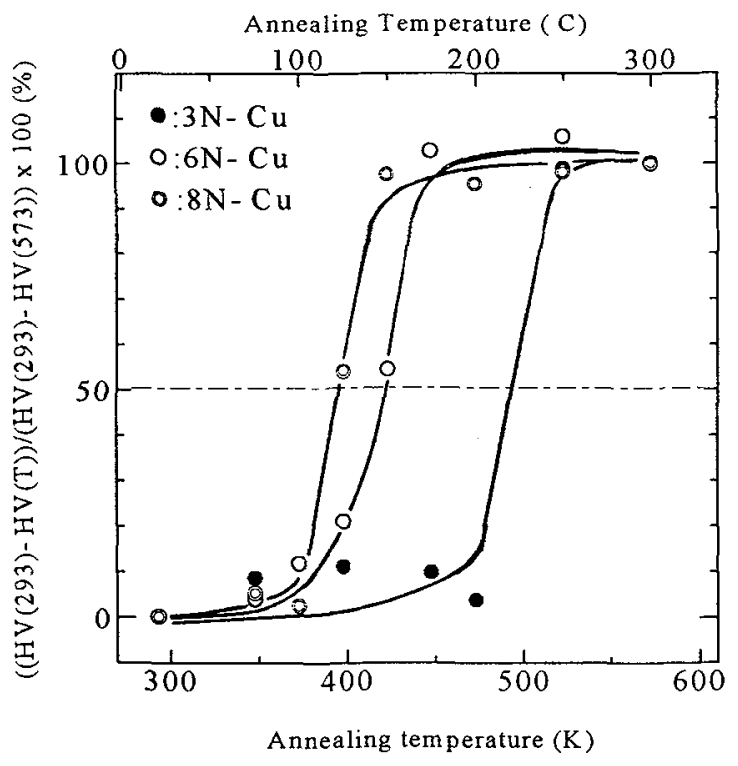

Figure 6 Static recrystallization behavior of pure coppers annealed for $30 \mathrm{~min}$ after cold deformed $83 \%$ in area 


\section{CONCLUSIONS}

(1) The ductility of ultra-high purity copper of $6 \mathrm{~N}$ and $8 \mathrm{~N}$ is much better than that of conventional copper of $3 \mathrm{~N}$ at room temperature.

(2) The ductility drop caused by intermediate temperature embrittlement is improved by an increase in purity because of decreasing dynamic recrystallization temperatures.

(3) The temperature of the ductility drop decreases with the increase in purity because of decreasing dynamic recrystallization temperatures.

(4) Intermediate temperature embrittlement is not affected only by sulphur content, but also by the total impurity content of pure copper.

\section{Acknowledgement}

The ultra-high purity copper of $6 \mathrm{~N}$ and $8 \mathrm{~N}$ was donated by the Japan Energy Co., Ltd. The impurity content of the specimens was also analyzed at the Japan Energy Co., Ltd. by GD-MS. We are grateful for its contribution to the present research.

\section{REFERENCES}

[1] M. Kato, "Application of Ultra-High-Purity Copper for Electric Wires and Conductors", Ultra-High Purity Base Metals, Kitakyusyu-City Japan 24-27 May 1994, K. Abiko, K. Hirokawa and S. Takaki (The Japan Institute of Metals, 1995) pp441-445

[2] A. Kurosaka, N. Tanabe, O. Kohno and H. Osanai, "High Purity Copper Wire", Ultra-High Purity Base Metals, Kitakyusyu-City Japan 24-27 May 1994, K. Abiko, K. Hirokawa and S. Takaki (The Japan. Institute of Metals, 1995) pp446-451

[3] J. N. Greenwood, D. R. Miller and J. W. Suiter, Acta Metall. 2 (1954) 250-258

[4] M. Ohmori, K. Wakasa and Y. Yoshinaga, J. Japan Inst. Metals 37 (1973) 1188-1194

[5] M. Ohmori and K. Wakasa, J. Japan Inst. Metals 37 (1973) 1195-1199

[6] M. Ohmori, Y. Sakakibara, K. Kaneko and Y. Yoshinaga, J. Japan Inst. Metals 40 (1976) 802-807

[7] O. Izumi, Japan Inst. Metals 18 (1979) 15-22

[8] S. Onaka, M. Kato and R. Tanaka, J. Japan Inst. Metals 50 (1986) 141-147

[9] H. Suzuki and G. Ito, J. Japan Inst. Metals 48 (1984) 1016-1021

[10] G. Ito, M. Kannno, H. Okamoto and N. Yamamoto, "Ductility of High Purity Copper at Intermediate Temperatures", Proc. Japan Inst. Metals, Narashino Japan 31 March - 2 April 1988, The Japan Institute of Metals, 1988 pp45

[11] T. Shibuyanagi, S. Saji and S. Hori, "Improvement of Low Ductility Failure in Copper", Proc. JIMIS4 Conf. on Grain Boundary Structure and Related Phenomena, Minakami Spa. Japan 25-29 November 1985, The Japan Institute of Metals, 1986 pp943-950

[12] M. Kanno and G. Ito, Japan Inst. Metals 27 (1988) 532-539

[13] T. Shibayanagi, A. Yoshimoto and S. Hori, J. Japan Inst. Metals 54 (1990) 9-16

[14] G. Itoh and M. Kanno, "Recrystalization in Copper Affected by Small Amount of Additional Elements", Recrystalization '90, Wollongong Australia 22-26 January 1990, T. Candra (The Materials, Metals \& Materials Society, 1990) pp579-583

[15] M. J. Luton and C. M. Sellars, Acta Metall. 17 (1969) 1033-1043

[16] R. Sandstrm and R. Lagneborg, Acta Metall. 23 (1975) 387-398

[17] S. Sakui and T. Sakai, Tetu To Hagane 63 (1977) 285-293

[18] S. Sakui, T. Sakai and K. Takeishi, Tetu To Hagane 62 (1976) 856-865

[19] T. Sakai and M. Ohashi, Tetu To Hagane 67 (1981) 2000-2009

[20] T. Sakai and J. J. Jonas, Acta Metall. 32 (1984) 189-209

[21] M. Ohashi, T. Endo and T. Sakai, J. Japan Inst. Metals 54 (1990) 435-441

[22] J. C. Fisher, Acta Metall. 3 (1955) 109-110 